\title{
A CONCEPTUAL AND EMPIRICAL MODEL OF SUPPLY CHAIN RISK MANAGEMENT MODEL IN INDONESIAN SMES
}

\section{Muhlis Madani ${ }^{1}$, Kittisak Jermsittiparsert ${ }^{2}$}

${ }^{1}$ Faculty of Social and Political Science, Muhammadiyah University of Makassar, South Sulawesi, Indonesia, ${ }^{2}$ Department for Management of Science and Technology Development, Ton Duc Thang University, Ho Chi Minh City, Vietnam ; Faculty of Social Sciences and Humanities, Ton Duc Thang University, Ho Chi Minh City, Vietnam. E-mail: ${ }^{1}$ muhlismadani@yahoo.co.id, ${ }^{2}$ kittisak.j@ @ chula.ac.th Article History: Received on $25^{\text {th }}$ February 2019, Revised on $28^{\text {th }}$ April 2019, Published on $25^{\text {th }}$ August 2019

\section{Abstract}

Purpose: The prime objective of the current study is to investigate the relationship between agile supply chain agility, supply chain integration and the supply chain risk in Indonesia SMEs. In addition to that the indirect relationship between and among the supply chain integration, supply chain agility and supply chain risk is examined.

Methodology: Employing the survey-based methodology, the SEM-PLS technique is used to test the hypothesized relationships. So, the current study has used SEM-PLS as a statistical tool to answer the research questions raised in this study and research objectives envisaged in the current study.

Results: The findings of the study have provided support to the theoretical foundation and proposed hypothesis of the current study. Current study will be helpful for policymakers and practitioners in understanding the issues related to supply chain risk, supply chain integration and supply chain agility. In the author's knowledge this is among very few pioneering studies on this issue.

Keywords: supply chain risk, Agility, Supply Chain, Indonesia.

\section{INTRODUCTION}

Rapid technological development, competitive advantage, and increasing globalization hamper the ability of a firm to manage and foresee behaviours of SC partners. Absence of such abilities to positively affect the behaviors of different organizations, within the supply chain causes significant SC risk (Tang and Musa, 2011; Krishna et al., 2018; Kyrychenko, 2018). Various cases of companies have been witnessed during the last two decades, regarding firms facing uncertain environment which in turn caused damage to the organizational performance. Such as, a fire incident in 2000 at Philips plant disrupted its manufacturing activities causing Ericsson a loss of around $\$ 400$ million (Tummala and Schoenherr, 2011). In 2011, in a similar manner, the production of Toyota has declined by 40,000 causing a daily loss of around $\$ 72$ million because of the occurrence of tsunami, nuclear disaster, and earthquake in Japan. Therefore, to overcome these kinds of losses, academia and practitioners have given much attention to the supply chain risk (Zhao et al., 2013).

Research related to Supply chain risk research is divided into two wider problems i.e. antecedents and sources associated with SCR, and consequences and management regarding SCR. Thus, supply chain risk has been argued to arise from a number of sources, i.e. regulatory regime, customer base and firm's supply, means of transportation, forecasting, firm size and labor issues (Kamalahmadi and Parast, 2016). Such factors together with efficiency objectives improve the network complexity, and consequently increase risks in the supply chain. Broadening the range of discussion about antecedent and sources of SC risk, numerous studies have empirically examined and proposed frameworks for the consequences and management related to SCR. Literature review and qualitative research provided various frameworks for supply chain risk management (Pettit et al., 2013).Such frameworks attempt to propose organizational programs and strategies for managing supply chain risk to maintain the competitive advantage position (Colicchia and Strozzi, 2012; Lee et al., 2018; Likitrattanaporn, 2018).

Resource based view is employed for this study, giving particular focus upon the DCV, for the purpose of proposing a relation among agility performance, supply chain integration and supply chain risk (Basheer et al., 2019). In earlier researches, dynamic capability view has been used extensively to understand the nature of association among organizational outcomes, and actions and supply chain uncertainties (Thun and Hoenig, 2011). Dynamic capability view states that firms operating under dynamic environment and are faced with supply chain uncertainties are required to generate capabilities for reducing supply chain risk and uncertainties. (Fan et al., 2017) stated that such dynamic capabilities improve coordination, joint action, and communication with different essential SC actors for sensing and capturing opportunities and reconfigure in order to adjust with the ecosystem. These capabilities facilitate in powerfully planning and executing the functions and desired outcomes of the firms (Qazi et al., 2018).

As a whole, the present study aims to present a detailed and novel explanation as well as empirical investigation that why supply chain risk encourages organizations to adopt supply chain integration, with the purpose of improve agility performance. The paper is put together as follows: the next section involves research framework and the set of proposed hypotheses. Followed by a research methodology involving data collection, scale development, hypotheses testing, and empirical results. Finally, the findings of the research are presented and discussed, followed by a conclusion based on the managerial and theoretical directions and implications for future studies. 


\section{HYPOTHESIS DEVELOPMENT}

\section{Dynamic capabilities view}

(Diabat et al., 2012) defined dynamic capability as an organizational ability of developing, reconfiguring and integrating external and internal resources for dealing with changing environment. Firms' dynamic capabilities may belong to three domains i.e. positions, paths, and processes. Where positions represent current intellectual property and technological endowment of a firm and the upstream relation among suppliers and customer base of a firm. Paths represents the strategic alternatives that are existing for the firms as well as the fascinating opportunities available in their paths. Whereas, processes represent the patterns and routines of current learning and practices of a firm. According to (Abrahamsson et al., 2015), dynamic capability view states that during unstable ecosystem, firm is expected to reinvest continuously in itself. Therefore, those dynamic capabilities are developed by the firms which lend firm the mechanism of directing external and internal resources having consistent imperatives and market needs.

\section{Supply chain integration (SCI) and supply chain risk (SCR)}

Organizations intensively and continuously share information and scan supply chain environment between organizations' basic functional units (Brusset and Teller, 2017). It has been argued by scholars that environmental uncertainty calls for the requirement of scanning supply chain environment, specifically using human interaction as it is thought to be much quicker and richer (Villar et al., 2014). Such interacting and scanning routines establish specialized and unique knowledge and relationships within an organization. Scanning is important as environmental changes demand quick readjustments and changes in operational actions, plans, and strategies. Critical role is played by knowledge sharing on demand-sides variations arising from sales unit and marketing, and supply-side variations arising from the purchasing unit, in the sense making and organizational analysis. It usually takes place through direct interaction with the internal customers for clearly understanding the requirements, and then codify them into a logical statement in accordance with the requirement as well as their effective conversion by transferring them into the supply market (Lin and Wu, 2014). Such provision to organizational stakeholders is considered to be a basic input for tactical and operational decision-making. The strength of actions and strategies has been increasing due to relevant stakeholders' inclusion and availability of needed information, during the decision-making process. Therefore, supply chain risk could result in joint decision-making and more information sharing among its stakeholders. Thus, the hypothesis is proposed as:

\section{H1. Internal integration increases with the increase in supply chain risk of a firm.}

From the dynamic capability view, it has been argued by scholars that supplier integration is a dynamic capability, which is required for adapting with the environmental changes (Helfat et al., 2009). This view also proposes that buyers seek to improve their collaboration and communication processes within their potential and existing partners, i.e. suppliers, under dynamic environment. Therefore, it can be stated that SCR encourages organizations to collaborate and work closely with its suppliers, in order to understand supply chain and to become adaptable with the functions of supply.

Collaboration and communication along with suppliers offer an important route for supply market scanning, affecting the behavior and decision-making of suppliers and learning from suppliers (Hafeez et al., 2018). Such supply chain processes provide mechanism for understanding, establishing, and taking advantage of the capabilities of suppliers. For instance, collaborative buyers attempt to participate with the supplier for expanding the level of cooperation, even under disruptive or unusual conditions (Lavastre et al., 2014). These relationships and understanding allow buyers to reconfigure and explore the capabilities and resources of key suppliers for managing SCRs (Huo et al., 2014). Therefore, under risky and uncertain environment, buyers seek to develop various ways for enriching connection among the key suppliers. Thus, the following hypothesis is proposed:

\section{H2. Supplier integration by the firm increases with the increase in supply chain risk.}

Finally, firms operating under dynamic environment tries to develop needed capabilities to sense and react with changing market demands (Xu et al., 2014). Taking into account the dynamic capabilities view, it is argued that environments that are attributed with high uncertainty, push firms to develop those operations which could work as dynamic capabilities for generating, circulating relevant functionaries, as well as reacting in accordance with the market intelligence (Park et al., 2016). Similarly, environmental turbulence, arising from frequent competitive landscape variations, increased globalization, and interdependence, is considered to be a key factor to improve production-distribution integration of a firm. Therefore, under unpredictable situation, firms attempt to integrate with its customers, as closely looking into demands of customers as well as the delivery mechanism help firms to foresee potential challenges and customer behavior in delivery processes (Handfield et al., 2015). In a similar manner, process development and joint products, help to incorporate and untangle customer's voice, thus allowing organizational outcomes to become in line with the market requirement (Gligor et al., 2016). Such coordination and mutual understanding allow companies to reconfigure both its external and internal resources appropriately and quickly adapt to environmental variations. Uncertain and unpredictable market demand causes firms to retain business continuity and make long-term contracts (Vanpoucke et al., 2014). Therefore, it can be stated that SCR compels organizations to build platforms and processes for joint value creation and sharing information with the end users. Hence, we propose the following hypothesis: 
H3. Firm increases customer integration with the increase in supply chain risk.

\section{Agility performance and Supply chain integration}

Extending the RBV, the dynamic capability view suggests that variations in organizational performance can somehow represents with the diversity of dynamic capability, which is embedded in high performance, seeking to utilize organization' external and internal resources (Flynn et al., 2010). Competitive advantage of a firm is contributed by effective dynamic capabilities, through permitting temporary benefits and allowing organizations to stay competitive and ahead of its competitors (Khan and Wisner, 2019). In this regard, development of business model and new forms of organizations and the establishment of new processes leads to superior performance of organization (Teece, 2007). For instance, (Tarafdar and Qrunfleh, 2017) suggested that dynamic capabilities allow quick reconfiguration of SC, ensuring enough potential particularly in rapidly changing and dynamic global environment. Therefore, supply chain integration results in improved organizational performance (Chan et al., 2017). Furthermore, Supply chain integration, being a dynamic capability increases the partners understanding about every one's businesses and assist partners in developing new routines for them. However, focus and coordinated efforts are made to fulfill collective objectives and aims that increase and accelerate the organizational response and resources to the requirements of the customers (Jajja et al., 2018). Therefore, following hypothesis is stated as:

\section{H4. Agility performance is positively affected by internal integration.}

Sourcing dynamic capabilities offer important means of obtaining higher agility performance (Dubey et al., 2018). Supplier integration constituents' i.e. collaborative and cooperative decision-making, information sharing, and relational and informal orientation improves agility performance of buyer firms (Dubey et al., 2018). Specifically, these buyersupplier associations help in exploiting innovative, specialized human resources and investments of suppliers. Increased coordination and communication is a buyer-supplier duo attributed with a higher understanding about their mutual needs and demands (Jajja et al., 2017). This mutual coordination assists in the focused attempt of reacting against market requirements. In addition, increased supplier integration is represented in terms of joint decision-making, providing much belief to the top suppliers. Successive mutual ownership and joint planning encourage better allocation of resources to satisfy SC objectives. Moreover, increased integration recommends intensive information exchange which is necessary for product modification and for new product development (Jajja et al., 2018). Such research findings indicating higher supplier integration offers firm a powerful mechanism for excelling in the agility performance. The hypothesis is stated as follows:

\section{H5: Agility performance is positively influenced by supplier integration.}

Customers' involvement in focal firms' early product development stages can give insights regarding product manufacturability and its effectiveness (Yan and Dooley, 2013). In a similar context, at the advance stage, such collaborative approach could boost up the process and product development. Customer involvement provides infrastructure and complementary knowledge which enhances number of products and its product value. However, (Tarafdar and Qrunfleh, 2017) argued that operational integration with customers, can prove to be helpful in improving response time and preparation of customization requests appeared from the customers. Furthermore, constant key customer interaction could minimize the information flow lag to key suppliers and stakeholders within the SC and also brings a sense of demand (Vanpoucke et al., 2014) Such information sharing reduces demand hikes and ordering costs and the following under and over stocking, thus increasing operating efficiency across the SC. Therefore, collaborative planning, jointly-managed inventories and real-time information sharing stimulate more responsiveness to changing market needs for variations in product mix and volume (Jajja et al., 2017). Following hypothesis is proposed on these arguments:

\section{H6. Agility performance is positively affected by customer integration.}

\section{Mediation effects}

It has been argued in the literature that internal integration mostly follows the external integration process. It does not recommend that internal integration is a prerequisite to external integration although, it offers support to the firm in effective customer and supplier integration. It is largely due to coordination among organization's functional units and information sharing that improves organizational ability of engaging effectively with stakeholders, such as customers and suppliers (Brusset and Teller, 2017). Earlier studies have suggested that customer and supplier integration is positively affected by internal integration. Uniting previous findings of positive association among customer-supplier integration and internal integration with $\mathrm{H} 1, \mathrm{H} 2, \& \mathrm{H} 3$, thus we hypothesize as follows:

H7. The relationship between supplier integration and supply chain risk is mediated by internal integration.

H8. The relation among customer integration and supply chain risk is mediated by internal integration.

Internal integration supports in supplier-customer integration resulting in increased agility performance (Hafeez et al., 2018). Thus, it can be stated that agility performance is expected to be affected by internal integration through customer and supplier integration. Thus, the mediating role of customer and supplier integration in the performance measures and internal integration relation is found to be inconsistent. Such as, (Handfield et al., 2015) proposed in their study that the relationship among product innovation \& quality and internal integration is not mediated by supplier integration. 
Contrarily, it is reported in a study that the relation among operational performance and internal integration of networked plants is found to be mediated by external integration i.e. through supplier and customer integration (Fan et al., 2017). These findings are inconsistent and further calls for the need to empirically analyse this association. Combining prior findings i.e. positive association of customer and supplier integration with internal integration and H4, H5, \& H6 hypotheses, we thus hypothesize as follows:

H9. The relation among agility performance and internal integration is partially mediated by supplier integration. H10. The relation among agility performance and internal integration is partially mediated by customer integration.

Literature on supply chain and dynamic capability view suggests that under dynamic environment, agility performance of an organization is a key element having influence on the long-term competitiveness of organization (Khan and Wisner, 2019). Therefore, organizations that function under SCR, tend to be more agile, as agility is considered to be a risk management strategy for the firm. In addition, supply chain risk encourages organizations to establish organizational structure for improving integration of external SC partners with the internal units, thus, leading to enhance agility performance and depicting relevance with a strategy-structure-performance pattern of supply chain, asserting that supply chain strategy of a firm that is developed by considering the external factors of environment acts as a driver of organizational processes and structure development that is expected to influence organizational performance. From H1-H6 hypotheses, observing the role of integration such as customer, supplier and internal integration to be the antecedents of agility performance and a consequence of SCR. However, this mediating role has not been analysed in prior studies. Therefore, we hypothesize as follows:

H11. The relation among supply chain agility performance and risk is mediated by internal integration.

H12. The relation among supply chain agility performance and risk is mediated by supplier integration

H13. The relation among supply chain agility performance and risk is mediated by customer integration.

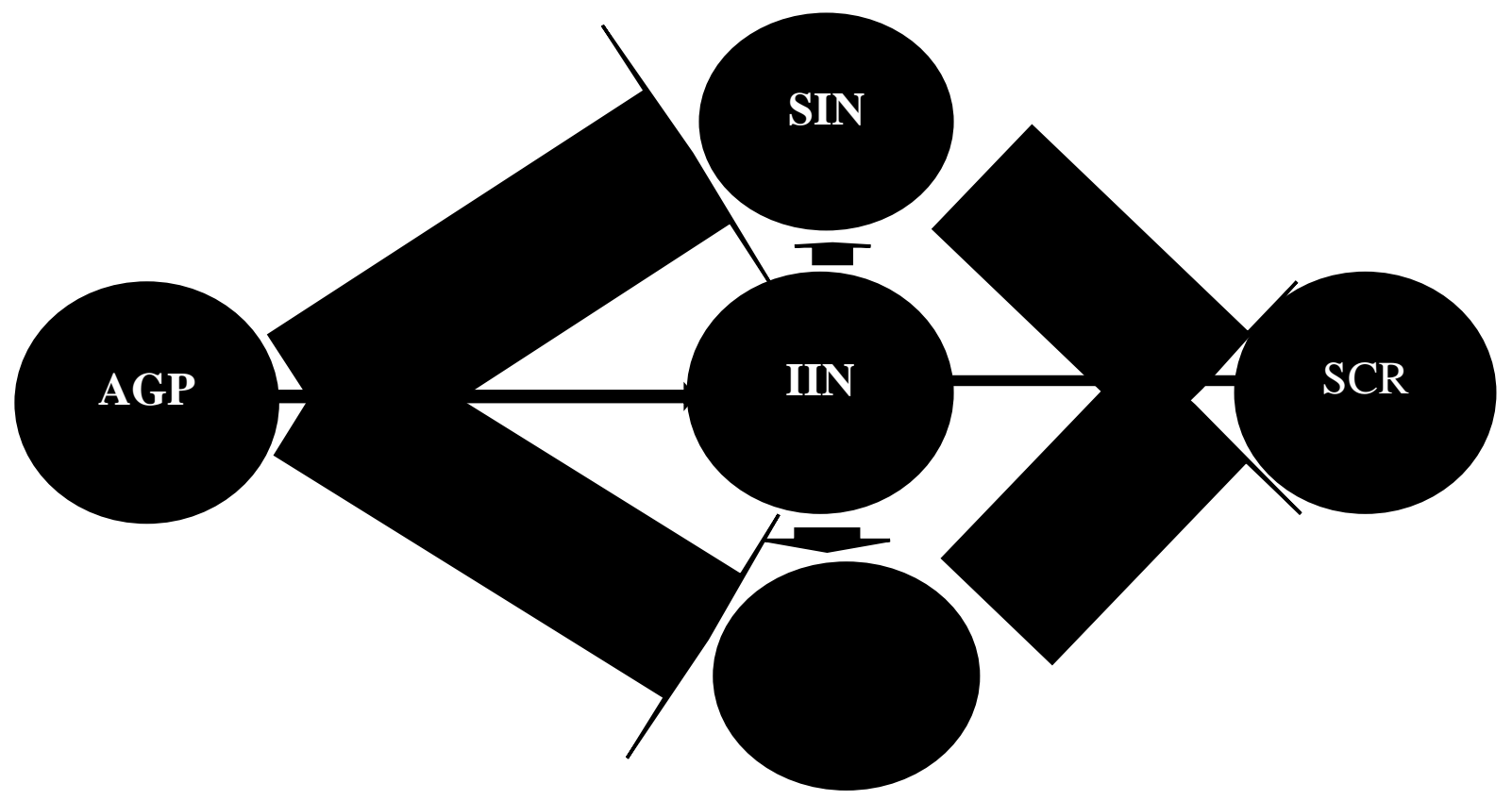

Figure 1: Conceptual Framework

\section{METHODOLOGY}

The items that are added for constructing the scales for this study have been taken from the previous research (Hameed $e t$ al., 2018) to confirm the content validity. Furthermore, a Likert scale is employed to collect the responses. The scale of 1-7 is used where 1 represents strongly disagree and 7 represents strongly agree, for the long-term relation of variables of logistic integration, information sharing, and information technology. Original names of the constructs are used except for the variable of communication which is then replaced with information sharing. Only one item from the logistics integration has been excluded, as that item comprises of material and information flow having conflict with the developed framework, since this study aims to distinguish and observe the nature of relationship among these flows. Furthermore, the operational performance consists of four dimensions, i.e. cost, delivery, flexibility, and quality. Therefore, in this context, respondents were guided to assess their level of performance from 1-7 as compared to their competitors, where 1 represents weakest in the industry and 7 represents the strongest. Partial Least Squares technique is called a secondgeneration structural equation modeling. This technique is compatible with structural equation models that have latent variables and a series of cause-and-effect relationships. Furthermore, (Jajja et al., 2017; Dubey et al., 2018) stated that PLS is perfect for statistical model building and prediction. 


\section{RESULTS}

This PLS-SEM was used in this study for the following reasons. Firstly, the PLS path modeling is more convenient to use when models are complex and it is more advantageous for real world applications (Yan and Dooley, 2013). This study examines the relationship between the independent variables and dependent variable. In addition, this study assesses the moderating effect on these relations. The second reason was that the PLS path modeling can be used with normal and nonnormal data. In the majority of social science studies, data tend to be less normal and, hence, PLS is able to address this issue. which make it one of the most powerful statistical techniques. Based on the above discussion, the researcher used the PLS path modeling to assess the hypothesized relationships, the constructs 'validity and reliability

In the PLS path model, composite reliability is the appropriate way to assess the internal consistency reliability. It can be interpreted like a Cronbach's $\alpha$. In other words, the composite reliability value should be more than 0.7 . Table 1 presents the information regarding the composite reliability of each variable. This table shows that the composite reliability value of each variable ranged from 0.844 to 0.985 , which was more than the benchmark of 0.70 . Convergent validity is explained by (Jajja et al., 2018) as to what extent various items measure the same variable. Based on recommendation, convergent validity was checked in this study by assessing the average variance extracted (AVE). The AVE value should be at least 0.5 for each variable to be sufficient. Following this procedure, the items with lowest loadings were omitted from the data set to improve the AVE value.

\section{Table 1: Reliability}

\begin{tabular}{c|c|c|c} 
& CR & AVE & Cronbach Alpha \\
\hline SCR & 0.975 & 0.872 & 0.885 \\
\hline SIN & 0.702 & 0.737 & 0.924 \\
\hline IIN & 0.960 & 0.871 & 0.893 \\
\hline CIN & 0.802 & 0.832 & 0.916 \\
\hline AGSC & 0.891 & 0.801 & 0.993 \\
\hline
\end{tabular}

Discriminant validity is described as the degree to which items differentiate among constructs or measure distinct concepts. Also, (Handfield et al., 2015) defined it as the level to which each study variable is different from other study variables. The discriminant validity was checked by two measures as recommended by (Hair et al., 2011) i.e. the Fornell-Larcker's criterion and cross-loadings. In the Fornell-Larcker's measure, the square roots of average variance extracted (AVE) of each variable should be more than the correlations among all other variables. Consistent with this criterion, the square root of the average variance extracted (AVE) of each study variable was higher than the correlations among other variables except the attitude variable. Thus, five attitude items with the lowest loadings were omitted from the data set and only 68 items were retained as they had loadings between 0.581 and 0.881 . After omitting these items, the square root of the average variance extracted (AVE) of each study variable was higher than the correlations among other variables, indicating appropriate discriminant validity. Table ..... presents the square roots of the average variance extracted (AVE) which appears in boldface and latent variable correlations which appear in lightface.

Table 2: Discriminant Validity

\begin{tabular}{c|c|c|c|c}
\hline & $\mathbf{( \beta )}$ & SD & T-value & P-Values \\
\hline H7 & 0.211 & 0.135 & 3.211 & 0.000 \\
\hline H8 & 0.357 & 0.152 & 3.678 & 0.000 \\
\hline H9 & 0.453 & 0.187 & 3.768 & 0.000 \\
\hline H10 & 0.408 & 0.132 & 3.968 & 0.000 \\
\hline H11 & 0.345 & 0.172 & 4.021 & 0.000 \\
\hline H12 & 0.432 & 0.252 & 4.201 & 0.000 \\
\hline H13 & 0.542 & 0.162 & 4.012 & 0.000 \\
\hline
\end{tabular}

The significance of the path coefficients was assessed using the standard bootstrapping procedure, which included 5000 bootstrap samples and 266 cases as recommended.

Table 3: Direct Effect

\begin{tabular}{c|c|c|c|c}
\hline & $\mathbf{( \beta )}$ & SD & T-value & P-Values \\
\hline H1 & 0.211 & 0.135 & 3.211 & 0.000 \\
\hline H2 & 0.357 & 0.152 & 3.678 & 0.000 \\
\hline H3 & 0.321 & 0.178 & 3.321 & 0.000 \\
\hline H4 & 0.342 & 0.165 & 3.234 & 0.000 \\
\hline H5 & 0.451 & 0.221 & 3.345 & 0.000 \\
\hline H6 & 0532 & 0.143 & 3.732 & 0.000 \\
\hline
\end{tabular}

The mediation is shown in table 4 
Table 4: Indirect Effect

\begin{tabular}{c|c|c|c|c|c}
\hline & $\mathbf{1}$ & $\mathbf{2}$ & $\mathbf{3}$ & $\mathbf{4}$ & $\mathbf{5}$ \\
\hline SCR & $\mathbf{0 . 7 0 9}$ & & & & \\
\hline SIN & 0.680 & $\mathbf{0 . 7 2 7}$ & & & \\
\hline IIN & 0.657 & 0.676 & $\mathbf{0 . 7 1 2}$ & & \\
\hline CIN & 0.642 & 0.654 & 0.682 & $\mathbf{0 . 8 3 2}$ & $\mathbf{0 . 8 7 2}$ \\
\hline AGSC & 0.627 & 0.641 & 0.653 & 0.732 & \\
\hline
\end{tabular}

Based on (Hair et al., 2011; Loukil, 2017; Luong et al., 2017; Loroun et al., 2018) suggestion, researchers who use PLSSEM should apply measures to indicate the models predictive relevance to evaluate the models quality. This study relies on Stone-Geisser's test of predictive relevance using blindfolding procedures. This test is usually used to assess the goodnessof-fit in PLS-SEM modeling predictive relevance.

\section{CONCLUSION}

As a whole, the present study aims to present a detailed and novel explanation as well as empirical investigation that why supply chain risk encourages organizations to adopt supply chain integration, with the purpose of improve agility performance. The prime objective of the current study is to investigate the relationship between agile supply chain agility, supply chain integration and the supply chain risk in Indonesia SMEs. In addition to that the indirect relationship between and among the supply chain integration, supply chain agility and supply chain risk is examined. Employing the surveybased methodology, the SEM-PLS technique is used to test the hypothesized relationships. So, the current study has used SEM-PLS as a statistical tool to answer the research questions raised in this study and research objectives envisaged in the current study. The findings of the study have provided support to the theoretical foundation and proposed hypothesis of the current study. Current study will be helpful for policymakers and practitioners in understanding the issues related to supply chain risk, supply chain integration and supply chain agility. In author knowledge this is among very few pioneering studies on this issue. Resource based view is employed for this study, giving particular focus upon the DCV, for the purpose of proposing a relation among agility performance, supply chain integration and supply chain risk. In earlier researches, dynamic capability view has been used extensively to understand the nature of association among organizational outcomes, and actions and supply chain uncertainties. Dynamic capability view states that firms operating under dynamic environment and are faced with supply chain uncertainties are required to generate capabilities for reducing supply chain risk and uncertainties. According to the study such dynamic capabilities improve coordination, joint action, and communication with different essential SC actors for sensing and capturing opportunities and reconfigure in order to adjust with the ecosystem. These capabilities facilitate in powerfully planning and executing the functions and desired outcomes of the firms. The paper is put together as follows: the next section involves research framework and the set of proposed hypotheses. Followed by a research methodology involving data collection, scale development, hypotheses testing, and empirical results. Finally, the findings of the research are presented and discussed, followed by a conclusion based on the managerial and theoretical directions and implications for future studies. According to the current study, the strength of actions and strategies has been increasing due to relevant stakeholders' inclusion and availability of needed information, during the decision-making process. Therefore, supply chain risk could result in joint decision-making and more information sharing among its stakeholders.

\section{REFERENCES}

1. Abrahamsson, S., F. Bertoni, A. Mol and R.I. Martín, 2015. Living with omega-3: New materialism and enduring concerns. Environment and Planning D: Society and Space, 33(1): 4-19. https://doi.org/10.1068/d14086p

2. Basheer, M., M. Siam, A. Awn and S. Hassan, 2019. Exploring the role of tqm and supply chain practices for firm supply performance in the presence of information technology capabilities and supply chain technology adoption: A case of textile firms in pakistan. Uncertain Supply Chain Management, 7(2): 275-288. https://doi.org/10.5267/j.uscm.2018.9.001

3. Brusset, X. and C. Teller, 2017. Supply chain capabilities, risks, and resilience. International Journal of Production Economics, 184: 59-68.https://doi.org/10.1016/j.ijpe.2016.09.008

4. Chan, A.T., E.W. Ngai and K.K. Moon, 2017. The effects of strategic and manufacturing flexibilities and supply chain agility on firm performance in the fashion industry. European Journal of Operational Research, 259(2): 486499.https://doi.org/10.1016/j.ejor.2016.11.006

5. Colicchia, C. and F. Strozzi, 2012. Supply chain risk management: A new methodology for a systematic literature review. Supply Chain Management: An International Journal, 17(4): 403-418. https://doi.org/10.1108/13598541211246558

6. Diabat, A., K. Govindan and V.V. Panicker, 2012. Supply chain risk management and its mitigation in a food industry. International Journal of Production Research, 50(11): 3039-

3050.https://doi.org/10.1080/00207543.2011.588619 
7. Dubey, R., N. Altay, A. Gunasekaran, C. Blome, T. Papadopoulos and S.J. Childe, 2018. Supply chain agility, adaptability and alignment: Empirical evidence from the indian auto components industry. International Journal of Operations \& Production Management, 38(1): 129-148.https://doi.org/10.1108/IJOPM-04-2016-0173

8. Fan, H., G. Li, H. Sun and T. Cheng, 2017. An information processing perspective on supply chain risk management: Antecedents, mechanism, and consequences. International Journal of Production Economics, 185: 63-75.https://doi.org/10.1016/j.ijpe.2016.11.015

9. Flynn, B.B., B. Huo and X. Zhao, 2010. The impact of supply chain integration on performance: A contingency and configuration approach. Journal of operations management, 28(1): 58-

71.https://doi.org/10.1016/j.jom.2009.06.001

10. Gligor, D.M., M.C. Holcomb and J. Feizabadi, 2016. An exploration of the strategic antecedents of firm supply chain agility: The role of a firm's orientations. International Journal of Production Economics, 179: 24-34. https://doi.org/10.1016/j.ijpe.2016.05.008

11. Hafeez, M.H., M.F. Basheer, M. Rafique and S.H. Siddiqui, 2018. Exploring the links between tqm practices, business innovativeness and firm performance: An emerging market perspective. Pakistan Journal of Social Sciences (PJSS), 38(2): 485-500.

12. Hair, J.F., C.M. Ringle and M. Sarstedt, 2011. Pls-sem: Indeed a silver bullet. Journal of Marketing Theory and Practice, 19(2): 139-152.https://doi.org/10.2753/MTP1069-6679190202

13. Hameed, W.U., M.F. Basheer, J. Iqbal, A. Anwar and H.K. Ahmad, 2018. Determinants of firm's open innovation performance and the role of $\mathrm{r} \& \mathrm{~d}$ department: An empirical evidence from malaysian sme's. Journal of Global Entrepreneurship Research, 8(1): 29.https://doi.org/10.1186/s40497-018-0112-8

14. Handfield, R.B., P.D. Cousins, B. Lawson and K.J. Petersen, 2015. How can supply management really improve performance? A knowledge-based model of alignment capabilities. Journal of Supply Chain Management, 51(3): 3-17.https://doi.org/10.1111/jscm.12066

15. Helfat, C.E., S. Finkelstein, W. Mitchell, M. Peteraf, H. Singh, D. Teece and S.G. Winter, 2009. Dynamic capabilities: Understanding strategic change in organizations. John Wiley \& Sons.

16. Huo, B., Y. Qi, Z. Wang and X. Zhao, 2014. The impact of supply chain integration on firm performance: The moderating role of competitive strategy. Supply Chain Management: An International Journal, 19(4): 369-384. https://doi.org/10.1108/SCM-03-2013-0096

17. Jajja, M.S.S., K.A. Chatha and S. Farooq, 2018. Impact of supply chain risk on agility performance: the Mediating role of supply chain integration. International Journal of Production Economics, 205: 118-138. https://doi.org/10.1016/j.ijpe.2018.08.032

18. Jajja, M.S.S., V.R. Kannan, S.A. Brah and S.Z. Hassan, 2017. Linkages between firm innovation strategy, suppliers, product innovation, and business performance: Insights from resource dependence theory. International Journal of Operations \& Production Management, 37(8): 1054-1075.https://doi.org/10.1108/IJOPM-09-2014-0424

19. Kamalahmadi, M. and M.M. Parast, 2016. A review of the literature on the principles of enterprise and supply chain resilience: Major findings and directions for future research. International Journal of Production Economics, 171: 116-133.https://doi.org/10.1016/j.ijpe.2015.10.023

20. Khan, H. and J.D. Wisner, 2019. Supply chain integration, learning, and agility: Effects on performance. Journal of Operations and Supply Chain Management, 12(1): 14.https://doi.org/10.31387/oscm0360218

21. Krishna, M., C.Y. Mei, C.W. Cing, L.M. Yin, L.X. Hui, S.Y. Sheng and T.W. Lin, 2018. Internet abuse intention at workplace among employees: A malaysian perspective. Humanities, 6(4): 156-170. https://doi.org/10.18488/journal.73.2018.64.156.170

22. Kyrychenko, V., 2018. Indonesias higher education: Context, policy, and perspective. Asian Journal of Contemporary Education, 2(2): 159-172.https://doi.org/10.18488/journal.137.2018.22.159.172

23. Lavastre, O., A. Gunasekaran and A. Spalanzani, 2014. Effect of firm characteristics, supplier relationships and techniques used on supply chain risk management (scrm): An empirical investigation on french industrial firms. International Journal of Production Research, 52(11): 3381-3403.https://doi.org/10.1080/00207543.2013.878057

24. Lee, U.H.M.S., A. Ismail and N.S.A. Sanusi, 2018. Ethical climate as a determinant of organizational commitment. International Journal of Asian Social Science, 8(8): 534539.https://doi.org/10.18488/journal.1.2018.88.534.539

25. Likitrattanaporn, W., 2018. A study of language learning strategies for practical use through the process of cooperative learning. International Journal of Educational Technology and Learning, 3(1): 35-44. https://doi.org/10.20448/2003.31.35.44

26. Lin, Y. and L.-Y. Wu, 2014. Exploring the role of dynamic capabilities in firm performance under the resourcebased view framework. Journal of business research, 67(3): 407-413.https://doi.org/10.1016/j.jbusres.2012.12.019

27. Loroun, B.B., X. Ming and S.A. Ali, 2018. Investigation on smes features in both china and iran. International Journal of Business, Economics and Management, 5(2): 30-44.https://doi.org/10.18488/journal.62.2018.52.30.44 
28. Loukil, K., 2017. Technological innovation in central and eastern europe: What's the contribution of innovation policy? The Economics and Finance Letters, 4(1): 1-8.https://doi.org/10.18488/journal.29.2017.41.1.8

29. Luong, N.D., H.V. Long, N.K. Tuan and N.D. Thai, 2017. Properties of concrete containing rubber aggregate derived from discarded tires. Asian Review of Environmental and Earth Sciences, 4(1): 12-19. https://doi.org/10.20448/journal.506.2017.41.12.19

30. Park, K., H. Min and S. Min, 2016. Inter-relationship among risk taking propensity, supply chain security practices, and supply chain disruption occurrence. Journal of Purchasing and Supply Management, 22(2): 120130.https://doi.org/10.1016/j.pursup.2015.12.001

31. Pettit, T.J., K.L. Croxton and J. Fiksel, 2013. Ensuring supply chain resilience: Development and implementation of an assessment tool. Journal of Business Logistics, 34(1): 46-76.https://doi.org/10.1111/jbl.12009

32. Qazi, A., A. Dickson, J. Quigley and B. Gaudenzi, 2018. Supply chain risk network management: A Bayesian belief network and expected utility based approach for managing supply chain risks. International Journal of Production Economics, 196: 24-42.https://doi.org/10.1016/j.ijpe.2017.11.008

33. Tang, O. and S.N. Musa, 2011. Identifying risk issues and research advancements in supply chain risk management. International journal of production economics, 133(1): 2534.https://doi.org/10.1016/j.ijpe.2010.06.013

34. Tarafdar, M. and S. Qrunfleh, 2017. Agile supply chain strategy and supply chain performance: Complementary roles of supply chain practices and information systems capability for agility. International Journal of Production Research, 55(4): 925-938.https://doi.org/10.1080/00207543.2016.1203079

35. Teece, D.J., 2007. Explicating dynamic capabilities: The nature and microfoundations of (sustainable) enterprise performance. Strategic management journal, 28(13): 1319-1350.https://doi.org/10.1002/smj.640

36. Thun, J.-H. and D. Hoenig, 2011. An empirical analysis of supply chain risk management in the german automotive industry. International journal of production economics, 131(1): 242249.https://doi.org/10.1016/j.ijpe.2009.10.010

37. Tummala, R. and T. Schoenherr, 2011. Assessing and managing risks using the supply chain risk management process (scrmp). Supply Chain Management: An International Journal, 16(6): 474-483. https://doi.org/10.1108/13598541111171165

38. Vanpoucke, E., A. Vereecke and M. Wetzels, 2014. Developing supplier integration capabilities for sustainable competitive advantage: A dynamic capabilities approach. Journal of operations management, 32(7-8): 446-461. https://doi.org/10.1016/j.jom.2014.09.004

39. Villar, C., J. Alegre and J. Pla-Barber, 2014. Exploring the role of knowledge management practices on exports: A dynamic capabilities view. International Business Review, 23(1): 3844.https://doi.org/10.1016/j.ibusrev.2013.08.008

40. Xu, D., B. Huo and L. Sun, 2014. Relationships between intra-organizational resources, supply chain integration and business performance: An extended resource-based view. Industrial Management \& Data Systems, 114(8): 1186-1206.https://doi.org/10.1108/IMDS-05-2014-0156

41. Yan, T. and K.J. Dooley, 2013. Communication intensity, goal congruence, and uncertainty in buyer-supplier new product development. Journal of Operations Management, 31(7-8): 523542.https://doi.org/10.1016/j.jom.2013.10.001

42. Zhao, L., B. Huo, L. Sun and X. Zhao, 2013. The impact of supply chain risk on supply chain integration and company performance: A global investigation. Supply Chain Management: An International Journal, 18(2): 115131.https://doi.org/10.1108/13598541311318773 